\title{
Modal concord: a case study of Dutch主
}

\author{
Janneke Huitink \\ Radboud University Nijmegen
}

\begin{abstract}
The combination of a modal verb and a modal adverb that is similar in modal force (possibility/necessity) and flavor (epistemic/deontic, etc.) allows a concord interpretation in which the two modals somehow 'fuse' and communicate just a single modality. This paper presents a case study of modal concord, as it is exemplified in Dutch. It seems that speakers of this language tend to add modal adverbs to modal verbs in order to disambiguate the meaning of that verb. To deal with this phenomenon, I propose modal adverbs are domain restriction devices, not unlike if-clauses, but that come with additional information about the force of the quantifier for which they provide the restrictor.
\end{abstract}

\section{Introduction}

In linguistics, 'concord' refers to the phenomenon that a sentence in which several operators of the same kind occur, is interpreted as if it contained only one such operator. It is well-known that this may happen with negation ('negative concord'), but concord occurs with modal operators as well. As far as I know, this was first discovered by Halliday (1970) and Lyons (1977). In the best examples, a modal verb combines with a modal adverb:

(1) Possibly this gazebo may have been built by Sir Christopher Wren.

As noted by Halliday, this sentence expresses more or less the same content as either of the following, in which only one modal expression is used:

(2) a. Possibly this gazebo was built by Sir Christopher Wren.

b. This gazebo may have been built by Sir Christopher Wren.

The reader may feel that (1) presents the possibility that this gazebo was built by the famous architect as more tentative than (2a) or (2b). This may 
well be the case, but the point here is that (1) doesn't express that it is possible that it is possible that Sir Christopher Wren built this gazebo, but just that this is possible, which is puzzling given compositional semantics. If both possibly and may express a modality (and the interpretation (2a) and (2b) suggest that this is correct), it is expected by compositionality that (1) makes a doubly modalized statement. But observationally (1) involves only one layer of modality. ${ }^{1}$

To be sure, modal concord does not follow from modal logic, at least not under universally accepted principles. In order to make iterated modalities entail single modalities, the following principles would have to be valid, which means that the accessibility relation underlying the modal expressions involved in modal concord would have to be transitive and dense (free world variables are universally quantified over; I leave the proofs to the reader):

a. $\diamond \diamond \varphi \rightarrow \diamond \varphi \quad$ transitivity if $w R v$ and $v R u, w R u$

b. $\square \square \varphi \rightarrow \square \varphi$ density if $w R v$, there is a $u: w R u$ and $u R v$

But is it reasonable to assume that these principles hold? For epistemic modality, it probably is. That is, most researchers assume that epistemic modality satisfies positive and negative introspection, which correspond to transitivity and Euclidity respectively, and Euclidity in turn implies density. But it isn't clear that deontic accessibility relations have these properties. In Standard Deontic Logic (SDL) the deontic accessibility relation is only assumed to be serial, i.e. not transitive or dense. Thus, SDL is just the normal system $D$ (or $K D){ }^{2}$ Yet modal concord also happens with deontic modals, as was first pointed out by Geurts \& Huitink (2006). For example, the following Dutch sentence is completely natural, and strongly favors a

\footnotetext{
${ }^{1}$ The extra tentativity of (1) is probably a pragmatic effect due to the optionality of using two modals. Because the addressee knows that (1) has a simpler alternative, he assumes that the speaker must have had good reason to make the effort of expressing (1), and reads more into the sentence than is literally said, cf. Horn's (1984) division of pragmatic labor. Similar effects have been observed for negative concord in languages in which the use of double negatives isn't the only way to express negation. A case in point is Dutch (Zeijlstra 2004):

(i) Hij heeft nergens geen zin in.

he has nowhere no desire in

'He doesn't feel like doing anything at all.'

${ }^{2}$ SDL is basically the system proposed by von Wright (1951) except that he had the deontic operators combine with names of acts rather than with sentences, so that deontic operators could not be nested (formulas of the form $\square \square \varphi$ were not well-formed). Von Wright also rejected $\square(\varphi \vee \neg \varphi)$, but otherwise adhered to all basic principles of SDL. See McNamara (2008) for a full overview of SDL.
} 
concord interpretation:

(4) Alle deelnemers moeten zich verplicht registreren. all participants must self obligatorily register 'All participants must register.'

This sentence doesn't mean that all participants have to have to register, but just that they have to. Clearly, this does not follow from SDL. Of course, it is possible to strengthen SDL, and some logicians have indeed proposed to do so, but the appropriateness of this move is debated, and SDL remains the widest adopted system of deontic logic. ${ }^{3}$ It follows that modal concord can only be accounted for logically by adopting controversial principles. For this reason, it's worth looking at other places for an analysis. One of the aims of this paper is to provide such an alternative analysis.

Before delving into the relevant phenomena, I would like to explain why I won't be considering examples like the following in the present study:
a. Alice thought "O Mouse" must be the right way of speaking to a mouse. (Drubig 2001)
b. Jack wishes that you may be happy. (Portner 1997)

Drubig (2001) writes about (5a) that the complement of think is not the modal complex embedded under it, but rather the prejacent of this complex (i.e. the proposition that "O Mouse" is the right way of speaking to a mouse), which suggests that must is not interpreted. Something similar seems to hold true of (5b); Jack certainly doesn't just wish that it is possible that you will be happy, but that you will in fact be. Thus, it appears that may doesn't contribute to what Jack wishes. But although the interpretation of the modal verbs in (5) is reminiscent of modal concord (in particular in as far as there are selectional restrictions like 'wish goes with may but not with must'), there are two reasons for thinking that what goes on in (5) is in fact a different phenomenon. First, whatever mechanism underlies the interpretation of (5), this mechanism is clearly able to cross clause boundaries. But we will see in section 2 that 'modal concord proper' is subject to much tighter locality restrictions. Second, it is not that clear that the auxil-

\footnotetext{
${ }^{3}$ Much of the discussion centers not around the axioms in (3), but around the following axiom, championed by e.g. Prior (1955, 225), yet challenged by Chellas (1980, 193-194):

$$
\square(\square \varphi \rightarrow \varphi) \quad \text { secondary reflexiveness } \quad \text { if } w R v, \text { then } v R v
$$

Yet if this is adopted, $\square \square \varphi \rightarrow \square \varphi$ immediately follows, since $\square(\square \varphi \rightarrow \varphi) \rightarrow(\square \square \varphi \rightarrow \square \varphi)$ is just a special issue of the distribution axiom K. See Huitink (2008, 84-87) for further discussion.
} 
iaries are not interpreted. For instance, (5a) seems to involve some element of quotation: "Alice thought to herself: "OO Mouse" must be the right way of speaking to a mouse"'. That is, the writer seems to have included must to signal that Alice's 'mental speech' actually contained this word. And in (5b), may seems to express the optative mood, which typically occurs with wishes and hopes. In sum, it is not clear that the attitude verbs and modal verbs 'work together' to express one modality.

The goal of this paper is to gain a better understanding of what modal concord is. To the best of my knowledge, since Halliday and Lyons observed that there is such a thing as modal concord, not much more has happened in the literature (with the exception of some recent work by me in collaboration with Bart Geurts in (2006), and by Zeijlstra (2007), which we will discuss below). What is lacking at this moment is (i) a comprehensive phenomenology of modal concord (exactly which facts need to be explained?) and (ii) an account of these facts. I cannot completely fulfill these gaps, but with this paper I intend to make a first stab. In section 2 I will present the relevant data for one particular language: Dutch. After that, I will consider several ideas for analyzing modal concord in 3.

\section{Modal concord in Dutch}

Dutch, my native language, abounds in sentences in which modal adverbs reinforce the meaning of a modal auxiliary. As the following examples show, modal concord occurs with various types of modal flavor in this language:

(6) a. Iedereen in Nederland moet verplicht Nederlands leren. everyone in Netherlands must obligatorily Dutch learn 'Everyone in the Netherlands has to learn Dutch.'

b. Frank Rijkaard moet gedwongen weg bij Barcelona. Frank Rijkaard must forcedly away at Barcelona 'Frank Rijkaard has to leave Barcelona.'

c. Ik moet nodig plassen. (Ad Foolen p.c.)

I must necessarily pee

'I have to pee.'

d. Ze moest onbedaarlijk lachen. she must+PAST uncontrollably laugh

'She had to laugh.'

e. Dat moet ongetwijfeld zijn vrouw zijn.

that must undoubtedly his wife be

'That has to be his wife.' 
For all of these sentences, a concord reading is preferred. Yet in isolation, (most of) the modal adverbs in (6) would introduce a modal operator:
a. Verplicht Nederlands leren is niet leuk. obligatorily Dutch learn is not fun 'It isn't fun to obligatorily learn Dutch.'
b. Ongetwijfeld kent $u$ hem wel. undoubtedly know you him PARTICLE 'You undoubtedly know him.'

Moreover, the adverbs in (6) participate in double modal readings (i.e. compositional readings). If, for example, Rita Verdonk ${ }^{4}$ utters (6a), this sentence is likely to be understood as an expression of her opinion that everyone in the Netherlands should be obliged to learn Dutch. We then understand from the sentence that everyone isn't obliged to learn Dutch yet, and that Rita thinks that this should become an obligation. Clearly, this reading requires an independent interpretation of the verb and adverb. The concord reading is thus not the only one available. Below in section 3.1 we will see that this counts against analyzing modal concord in terms of syntactic agreement.

\subsection{Disambiguation}

We have just seen that in isolation, verplicht 'obligatorily' suffices to express deontic necessity, and so does moeten 'must'. One would therefore expect (6a) to make a doubly modalized statement. But although such a reading is possible, in the absence of contextual clues that this reading is intended, (6a) is interpreted as if it contained only one deontic modal. The same goes for the other sentences in (6). Why is that? The reason for this could be that we expect the speaker to have included the adverb in order to disambiguate the auxiliary. For instance, in (6b), gedwongen 'forcedly' intuitively gives additional information of the conditions under which Frank Rijkaard has to leave Barcelona. ${ }^{5}$ I heard (6b) on the TV news, where just uttering (8) (in which the adverb is left out) could easily have given rise to misunderstanding:

(8) Frank Rijkaard moet weg bij Barcelona.

Frank Rijkaard must away at Barcelona

'Frank Rijkaard has to leave Barcelona.'

\footnotetext{
${ }^{4}$ Rita Verdonk is a Dutch politician who is known for her unfriendly attitude towards immigrants.

${ }^{5}$ To be sure, we are talking about the Dutch ex-trainer of the soccer club F.C. Barcelona.
} 
Modal auxiliaries like moeten 'must' are typically compatible with a wide range of modal interpretations, depending on the set of circumstances which provides the intuitive background for the modal (Kratzer 1981). For example, (8) could mean that Rijkaard has to leave in view of his own wishes, say to take care of his sick grandmother, or it could mean that he has to leave in view of the speaker's wishes, or it could mean that he has to leave in view of his contract expiring, etc. In contrast, (6b) will not be misunderstood, for gedwongen is unambiguous: he has to leave in view of the board's wishes, not simply because of an expiring contract, but he was fired because his results have been poor. ${ }^{6}$

The combinatoric possibility of modal verbs and adverbs is subject to idiosyncratic restrictions. ${ }^{7}$ For example, one doesn't sound natural uttering $i k$ moet onbedaarlijk plassen 'I must uncontrollably pee', or ze moest nodig lachen 'she necessarily had to laugh'. In fact, onbedaarlijk is typically used to talk about laughter, or about crying: Ze moest onbedaarlijk huilen 'She uncontrollably had to cry'. Another typicality is that, at least in Dutch, dynamic possibility expressions only seem to participate in concord when they are in the scope of negation. The negation is then marked on the adverb: ${ }^{8}$
a. Ik kan onmogelijk op tijd komen.
I can impossibly on time come
'I cannot arrive on time.'

b. Ik ben met geen mogelijkheid in staat om te functioneren. I am with no possibility in state to function 'I am not able to function.'

Positive dynamic possibility modals do not get reinforced by modal adverbs. For instance, (10), in which kunnen 'can' combines with mogelijk 'possibly' (the positive counterpart of the adverb in (9a)), clearly makes a doubly modalized statement:

\footnotetext{
${ }^{6}$ In the sentences in (6), the adverbs are used to disambiguate the modal flavor (epistemic/deontic etc.) of the verbs, as this part of their meaning is left underspecified. But in other languages, modal verbs are underspecified with respect to their modal force (possibility/necessity). Interestingly, it turns out that this ambiguity can also be resolved by the addition of an adverb. Nauze $(2008,45-46)$ reports that in Fongbe, the adverb dàndàn ('necessarily/obligatorily') is used to force a strong deontic interpretation for verbs that in isolation also allow a weak deontic necessity reading.

${ }^{7}$ This need not be surprising. As noted by Greenbaum (1970, $83 \mathrm{ff}$.), the realm of lexical items expressing intensification abounds in fixed combinations.

${ }^{8}$ In this respect, Dutch is like German, cf. 'Ich kann unmöglich ... '. In English, negation would be marked on the modal: 'I can't possibly arrive on time'.
} 
(10) Ik kan mogelijk het plafond aanraken.

I can possibly the ceiling touch

'Perhaps I can touch the ceiling.'

This says that the speaker might have the ability to touch the ceiling.

Interestingly, those modal auxiliaries that do not get reinforced by adverbs appear to be exactly the ones that are more specialized in the modal flavor they express. Take the Dutch verb mogen. This modal is lexically specified to convey permission (i.e. unlike English may, mogen has no epistemic sense). There is thus little chance to be misunderstood if one uses this modal. We therefore expect that speakers will not be prompted to reinforce the meaning of mogen. As far as I know, this is borne out. In fact, there doesn't even exist an adverb which conveys permission in Dutch. ${ }^{9}$ Similar considerations might apply to positive kunnen 'can'. In Dutch, kunnen predominantly encodes ability (Nuyts 2001). In normal circumstances it will thus be clear which modal flavor is intended, and there will be no reason for adding additional emphasis. When kunnen is negated, however, it alternates between ability and epistemic interpretations. Accordingly, we find that reinforcement is frequent in negative contexts.

\subsection{Syntactic restrictions}

Modal concord is subject to locality constraints. More specifically: the verb and adverb have to be clause mates:

a. Het kan misschien gaan regenen.

$$
\begin{aligned}
& \text { it can perhaps go rain } \\
& \text { 'It might rain.' }
\end{aligned}
$$

b. Jan zei misschien dat het kan gaan regenen.

Jan said perhaps that it can go rain 'Perhaps Jan said that it might rain.'

\footnotetext{
${ }^{9}$ In Dutch, adverbs are usually identical to adjectives cf. het is verplicht/onmogelijk 'it is obligatory/impossible' vs. verplicht/onmogelijk 'obligatorily/impossibly'. The most likely candidate for a permission expressing adverb is therefore toegestaan, as one can form an adjectival phrase with this item: het is toegestaan dat ... 'it is permitted that ...'. Yet there doesn't seem to be an adverb toegestaan 'permissibly':

(i) *Jan mag toegestaan uitslapen.

'Jan may permissibly sleep late.'

This feels ungrammatical. In fact, according to my intuitions toegestaan just cannot be used as an adverb. Given that verb-adverb combinations have some disambiguating purpose, this is only to be expected.
} 
c. Als het kan gaan regenen, moeten we misschien een

if it can go rain, must we perhaps an paraplu meenemen.

umbrella bring

'If it might rain, we should perhaps bring an umbrella.'

Intuitively, misschien 'perhaps' and kunnen 'might' appear too far apart from each other in (11b) and (11c) for misschien to 'work its magic'. As a result, each modal contributes its own modal operator to the semantics of these sentences.

Although in many of the sentences above the verb and adverb occur in adjacent positions, this is not necessary:

$$
\begin{aligned}
& \text { Ik moest gisteren ontzettend nodig plassen. } \\
& \text { I must+PAST yesterday very much necessarily pee } \\
& \text { 'Yesterday I really had to pee.' }
\end{aligned}
$$

Here the verb and adverb are separated from one another. Still, the sentence expresses a concord interpretation.

Observations by Hoye (1997) suggest that in English, some verb-adverb combinations have to occur in a fixed order to participate in modal concord:
a. I can't possibly eat any more.
(concord)
b. You possibly can't eat any more.
(compositional)

While (13a) prefers a concord reading, (13b) is naturally read as an estimation of the chance that the addressee isn't able to eat anymore. This is obviously a compositional reading, in which the verb and the adverb both contribute a modality. For Dutch, however, I am not aware of such frozen combinations. In our examples, the only way to reverse the order of the expression is by fronting the adverb. This may make the sentence sound a bit odd, as the adverb then becomes topicalized, but it doesn't force a compositional interpretation:

a. Nodig moet ik plassen.

Necessarily must I pee

'I have to pee.'

b. Onmogelijk kan ik uitdrukking geven aan mijn liefde voor Impossibly can I expression give to my love for jou. you 'I cannot find the words to express my love for you.' 
Though (14b) is somewhat odd, (14a) is perfectly fine.

Finally, though modal concord is usually only optional in Dutch, there are some instances of obligatory modal concord. For example, the particle combination wel eens only has a modal meaning when it co-occurs with other modals. In (15a) wel eens expresses epistemic possibility and engages in concord with epistemic zou kunnen 'could', whereas in (15b) wel eens lacks this modal interpretation. Here wel eens contributes its ordinary temporal meaning:

a. Dat zou wel eens de vrouw van Jan kunnen zijn.

that would wel eens the wife of Jan can be

'That could well be Jan's wife.'

b. Heb jij Jan's vrouw wel eens gezien?

have you Jan's wife wel eens seen

'Have you ever seen Jan's wife?'

Interestingly, it seems that at least some particles from other languages also require obligatory modal concord. Grosz (2008) shows that the German discourse particles $J A$, ruhig, and bloß require the presence of a modal operator to be acceptable.

\subsection{Semantic restrictions}

Not any modal verb-adverb combination participates in modal concord. Rather:

[A] clear distinction can be drawn between pairs which are felt to be equivalent, and thus reinforce each other (as 'concord') when both are present, as in perhaps he might have built it, and those which are not equivalent and are thus cumulative in meaning, as in certainly he might have built it 'I insist that it is possible' or 'I grant that it is possible'). (Halliday 1970, 331)

For pairs like may certainly, a concord interpretation is intuitively unavailable due to a mismatch in modal force of the modals, certainly expressing universal and may existential quantification over possible worlds. Dutch modal concord is also subject to this restriction. That is, (16) has no concord reading:

Jan kan zeker thuis zijn.

Jan can certainly home be

'Jan might certainly be home.' 
Here the speaker is conceding that it is indeed possible that Jan is home, she is not just saying that this is possible. ${ }^{10}$

However, even for pairs of modals that do express the same modal force, a concord reading isn't guaranteed. For such a reading to be possible, the modals must also be equivalent in modal flavor. As far as I know, this was first pointed out by Geurts \& Huitink (2006). Consider:

Hij moet zeker in Parijs zijn,

he must certainly in Paris be

'He must (certainly) be in Paris,'

a. given that he just called from there. (concord)

b. in order to attend his business meeting. (compositional)

While zeker 'certainly' unambiguously conveys epistemic modality, moeten 'must' also allows non-epistemic interpretations. As a consequence, (17) is ambiguous between a concord interpretation and a compositional reading, brought out by the continuations in (17a) and (17b) respectively. (17a) presents a piece of evidence, which suggests that moeten is intended epistemically. As a result, moeten and zeker engage in concord. The continuation in (17b), however, makes a goal explicit, and this favors a teleological interpretation of the auxiliary. Apparently, this makes moeten incompatible with zeker (as far as concord in concerned), for a double modal reading arises: the speaker presumes that his presence is required in Paris. Note that in this double modal reading the epistemic modal takes wide scope, even though at surface it occurs under the teleological modal. In fact, sentence (17) has no compositional reading in which the scopal order is reversed. This could be due to the fact that the reverse order simply makes no sense (Papafragou 2000, ch. 3), or perhaps this points to rather deep differences between epistemic and non-epistemic modality (Cinque 1999, Nuyts 2001, 2004, Nauze 2008), but this is not the place for a in-dept comparison between these positions.

\footnotetext{
${ }^{10}$ Prima facie, examples like (i) seem to contradict the claim that the two modals must be equivalent in force, as moeten 'must' encodes necessity, but waarschijnlijk 'probably' encodes a value somewhere between necessity and possibility:

(i) Dat moet waarschijnlijk in 1943 zijn geweest. (Geurts \& Huitink 2006) that must probably in 1943 be been

'That was probably in 1943.'

Perhaps the verb and adverb only have to be 'close enough' in quantificational force. However, under Kratzer's (1981) analysis of probably as expressing human necessity, it does express universal quantification over possible worlds, but restricted to those worlds that correspond to the normal course of events.
} 
To sum up, the present section has identified three desiderata for a theory of modal concord. First, such a theory should account for the disambiguating function of modal concord. Second, a satisfactory analysis should account for the locality constraints on modal concord. Third and last, it should account for the fact that modal concord is only possible between verbs and adverbs that are equivalent in modal force and flavor. In the next section, we will use these desiderata to compare various ideas for analyzing modal concord.

\section{Analyzing modal concord}

Recently, two analyses of modal concord have been put forward. The first is Zeijlstra's (2007) syntactic agreement analysis, and the second is the semantic type-shifting analysis I proposed in collaboration with Bart Geurts in (2006). But I will argue that both approaches leave something to be desired. The agreement theory cannot deal with the fact that verb-adverb combinations can be ambiguous between a concord and a compositional reading. The type-shifting analysis can, but suffers from being rather stipulative. In 3.1, I will discuss the syntactic agreement theory, and in 3.2 I will discuss the semantic type-shifting analysis. Then, in 3.3, I will sketch an alternative, taking the middle ground between the two theories on the market. Following the semantic theory, I will propose that adverbs are ambiguous between a modal and a non-modal reading, but from the syntactic theory I will adopt the idea that adverbs, on their non-modal reading, have to agree with the verb in concord constructions.

\subsection{Modal concord as syntactic agreement}

Zeijlstra (2007) argues that concord readings arise because modal auxiliaries are semantically empty, while the restrictions on modal concord are the outcome of a syntactic agreement relation between modal auxiliaries and modal adverbs. This analysis is completely parallel to his (2004) analysis of negative concord. Following Chomsky's (1995) minimalist program, Zeijlstra adopts a feature theory according to which (possibly abstract) items either carry an interpretable feature $[\mathrm{iF}]$ or an uninterpretable feature $[\mathrm{uF}]$. These two kinds of features differ from one another in that interpretable features are semantically interpreted, while uninterpretable features are morphologically interpreted. This means that they must be checked against an interpretable feature of the same type. Zeijlstra argues that the relevant syntactic checking relation is that of agreement, hence that a feature [iF] can only check a feature $[\mathrm{uF}]$ if $[\mathrm{iF}] \mathrm{c}-\mathrm{commands}[\mathrm{uF}]$. 
The idea is now that modal auxiliaries are semantically empty markers of the presence of a (possibly covert) modal operator. That is, modal auxiliaries carry uninterpretable modal features that need to be checked by an operator with a suitable interpretable feature. Modal adverbs are such operators, i.e. they carry interpretable modal features. As the modal force of modal elements is (in most languages) lexically encoded, it makes sense to assume that this shows up in the featural decomposition. It is then predicted that (18) allows a concord reading, while (19) does not, because the verb and adverb do not match in quantificational force:

You may perhaps have read my paper. [CPyou perhaps ${ }_{[\mathrm{i} \diamond]}$ may $_{[\mathrm{u} \diamond]}$ have read may paper]

While the auxiliary can have its feature checked in (18), it can't in (19), for the auxiliary carries $[u \diamond]$ while the adverb carries $[i \square]$, which is of the wrong type (note that moving the adverb to a position in which it c-commands the auxiliary wouldn't help):

\section{It may necessarily be the case.}

$$
\text { [CP it may }{ }_{[\mathrm{u} \diamond]} \text { necessarily } \mathrm{i}_{[\mathrm{i}]]} \text { be the case] }
$$

Yet, the sentence is not ungrammatical, but it is interpreted as a doubly modalized statement. To account for this, Zeijlstra assumes that there must be a covert modal operator that checks the feature of the auxiliary may. This leads to the underlying structure in (20) for (18):

$$
\left[\mathrm{CP} \text { it } \mathrm{OP}_{[\mathrm{i} \diamond]} \operatorname{may}_{[\mathrm{u} \diamond]} \text { necessarily } \mathrm{y}_{[\mathrm{i} \square]}\right. \text { be the case] }
$$

Assuming that the covert modal has a meaning similar to that of the adverb perhaps, the sentence is predicted to convey that it is possible that it is necessarily the case.

In the agreement theory, the positing of abstract operators is a last resort strategy, which only applies if there are overt elements with $[\mathrm{uF}]$ which could not have been licensed by any other element:

Economy condition:

Only if a particular sentence is grammatical and none of the overt elements is responsible for the grammaticality of the sentence, must the sentence be grammatical due to a covert element. 
Besides in (20), covert modals are necessary to account for the interpretation of sentences in which modal auxiliaries occur on their own 'John may be home'.

Let's take stock, and consider in how far this analysis meets the three desiderata outline at the end of section 2. First, the theory accounts for the intuition that in concord constructions the adverbs are used to disambiguate the modal verb. On the agreement theory, a modal verb could be agreeing with a multitude of covert operators. Inclusion of an explicit adverb reduces this ambiguity. Second, in as far as syntactic agreement is clause-bounded, the locality constraints are accounted for. However, it seems that the third criterion is not fulfilled. Though the theory predicts that concord is only possible if the verb and adverb are similar in force, it doesn't require that the modals in a concord construction are similar in their modal flavor. It follows that the theory fails to predict compositional readings. Consider (22):

Perhaps $_{[\mathrm{i} \diamond]}$ John may $_{[\mathrm{u} \diamond]}$ become a doctor some day. (Zeijlstra 2007)

This sentence is ambiguous between a concord reading 'it is possible that John will become a doctor some day' and a compositional reading 'it is possible that John will receive permission to become a doctor some day'. Prima facie, the latter reading can only be explained on the assumption of the presence of a covert modal (since the auxiliary is meaningless). But the economy condition specifies that such operators can only be posited to avoid ungrammaticality, and (22) cannot in any way be said to be ungrammatical. All relevant features are checked. ${ }^{11}$

One might think that the problem can be solved by adopting features that encode modal flavor, such as as [iEPI] or [uDEO], as modal flavor certainly could be lexically encoded, and such a featural decomposition could perhaps even be motivated by pointing to syntactic differences between epistemic and deontic modals. However, sentences like (6a), which is repeated below, would remain problematic:

(23) Iedereen in Nederland moet verplicht Nederlands leren. everyone in Netherlands must obligatorily Dutch learn 'Everyone in the Netherlands has to learn Dutch.'

As discussed above, this sentence is ambiguous between a modal concord

\footnotetext{
${ }^{11}$ Aware of this problem, Zeijlstra says that "nothing forbids that modal auxiliaries are contextually specified for a modal type [flavor]". But he doesn't spell out how this 'contextual specification' is supposed to work, nor how this squares with the claim that modal auxiliaries are meaningless.
} 
reading and a double modal reading 'It should be the case that everyone in the Netherlands is obliged to learn Dutch'. It is hard to see how Zeijlstra's theory could ever predict the latter reading, for both modals have universal force, and both have deontic flavor. Thus, even if there were features for modal force and flavor, it would still not be necessary to postulate a covert operator. Of course, in the double modal reading, the modals each depend on a different set of norms, but it is not clear that this fact can be used to help the agreement theory. Though the type of conversational background that an expression combines with might be lexically encoded, its actual content is surely determined by the context of utterance.

To sum up, the problem for the agreement theory is that modal auxiliaries often are interpreted. In light of this, it just doesn't seem plausible that they are semantically empty. Recall that the agreement theory is meant to be a general theory of concord phenomena, including negative concord. Assuming that negative concord can be satisfactorily dealt with in terms of syntactic agreement (see Zeijlstra (2004) for arguments), why does it fail for modal concord? The problem seems to be that modal concord is less grammaticalized than negative concord is in so-called negative concord languages. In such languages, one semantic negation has to be marked twice in the syntax. For instance, in Italian, the only grammatical way to express that Gianni hasn't called anybody is by using both a negative marker non and an n-word nessuno:

$$
\begin{aligned}
& \text { Gianni *(non) ha telefonato a nessuno. (Zeijlstra 2004) } \\
& \text { Gianni not has called to nobody } \\
& \text { 'Gianni hasn't called anybody.' }
\end{aligned}
$$

The sentence becomes ungrammatical if non is left out; hence negative concord is obligatory. In contrast, modal concord is usually not obligatory. If verplicht 'obligatorily' is removed from (23), the sentence remains grammatical. The syntactic agreement theory seems to be a model for languages in which concord has become grammaticalized. It would suit modal concord well, if it were the case that moet verplicht 'must obligatorily' were the only way to express deontic necessity. In that case, the meaning of moeten would have been weakened to the point where it becomes virtually meaningless. But the theory doesn't fit the way modal concord contemporarily manifests itself in Dutch. ${ }^{12}$

\footnotetext{
${ }^{12}$ It is an interesting question whether modal concord will ever become grammaticalized. That is, is there something like a Jespersen cycle in the development of modality? To the best of my knowledge, there is no evidence that points in this direction. This is in spite of the fact that there is already quite a lot of diachronic research done (Sweetser 1990, Nordlinger \& Traugott 1997). One would expect that if there were a modal Jespersen
} 


\subsection{The type-shifting analysis}

An alternative analysis is proposed in Geurts \& Huitink (2006), where modal adverbs are treated as polysemous between their standard meaning and a 'functional' meaning. On this functional meaning, the adverb 'tests' whether its argument, the modal auxiliary, is of the right type, i.e. whether it has the same meaning as the adverb on its standard interpretation. If so, the function yields the meaning of the adverb as output, and a concord reading ensues.

The functional meaning results from applying the type-shift rule in (25b) to the meaning of the adverb. In these definitions, $P$ and $Q$ stand for operators of type $\langle s t, s t\rangle .{ }^{13}$ That is, assuming a simplified semantics for modal operators according to which these operators express relations between propositions, $P$ and $Q$ are variables over modal operators.

$$
\begin{array}{ll}
\text { a. } & \llbracket P \doteq Q \rrbracket^{\mathcal{M}, h}=\llbracket P \rrbracket \text { if } \llbracket P \rrbracket=\llbracket Q \rrbracket, \text { undefined otherwise } \\
\text { b. } & \lambda P \lambda Q . P \doteq Q \quad(=\llbracket(\mathbb{C} \rrbracket)
\end{array}
$$

The type-shifting rule in (25b) maps «perhaps》onto a function which yields

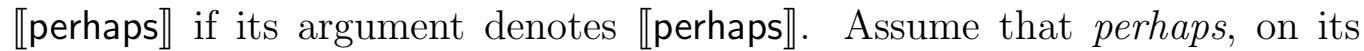
non-shifted reading, has the following meaning, which is equivalent to that of epistemic may. In the definitions below, $R$ is a constant denoting an epistemic accessibility relation: ${ }^{14}$

$$
\llbracket \text { perhaps } \rrbracket=\llbracket \text { may } \rrbracket=\lambda p \lambda w \cdot \exists v[w R v \& v \in p]
$$

The following sample derivation makes clear how this theory predicts a concord interpretation for 'Perhaps Barney may be asleep':

\footnotetext{
cycle, this would have been discovered by now.

${ }^{13} \mathrm{As}$ is common, $s$ is the type of possible worlds, and $t$ is the type of truth values. I shorten $\langle s, t\rangle$ to $\langle s t\rangle$.

${ }^{14}$ It is thus assumed that modal expressions are lexically ambiguous rather than underspecified (i.e. $R$ is a constant rather than a variable which is to receive a value by the assignment function). This is just to simplify: the theory can easily be reformulated taking into account that may is compatible with non-epistemic modal interpretations as well. See Huitink (2008, 99-101).
} 
$\lambda w . \exists v[w R v \& v \in \lambda w \cdot$ be asleep(Barney) $(w)$

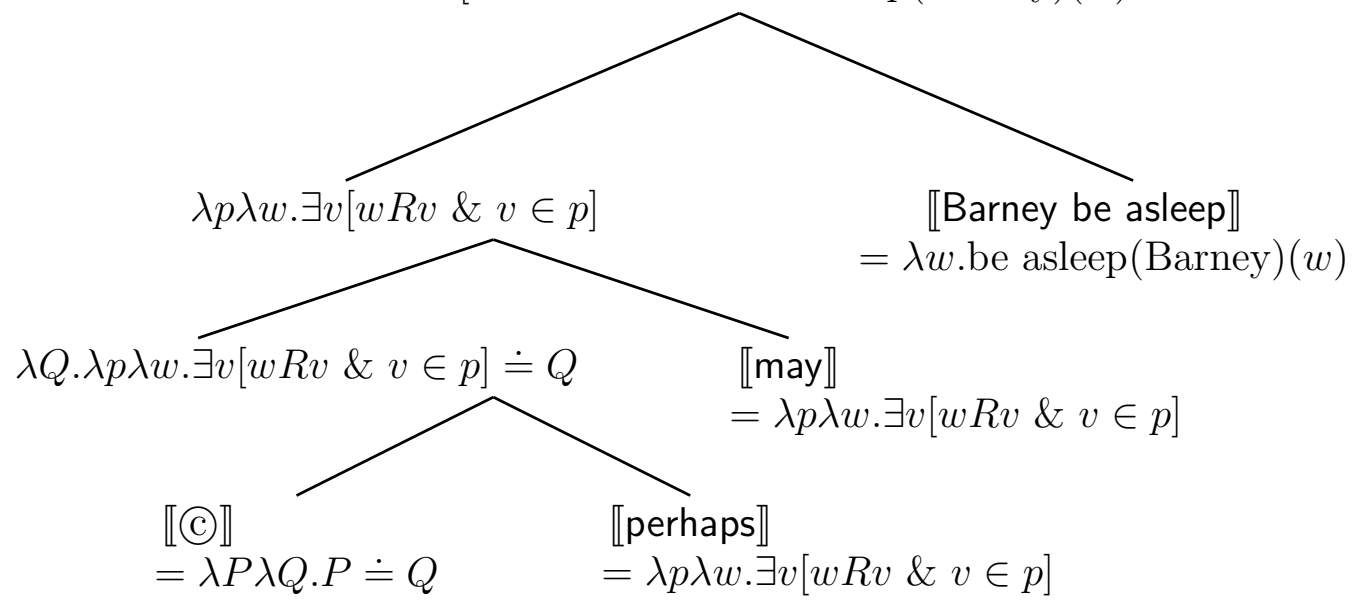

The interpretation predicted for 'Perhaps Barney may be asleep' is exactly the canonical interpretation for 'Barney may be asleep': there is an (epistemically) accessible world such that Barney is asleep in it.

Let's now ask how the type-shifting analysis copes with the three desiderata we have outlined. First, the analysis accounts for the disambiguating effect of modal adverbs. Only if may is interpreted epistemically will

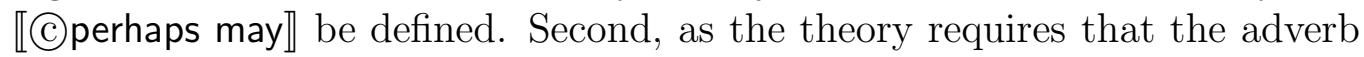
takes the modal auxiliary as its sister, the locality constraints can probably also be made to follow, though it should be noted that the right constituent structure cannot always straightforwardly be derived from the surface syntax. That is, in order to really account for the syntactic restrictions on modal concord, the type-shifting theory must be augmented with some restructuring mechanism yet to be defined. ${ }^{15}$ The semantic restrictions, on the other hand, are accounted for. On their functional meaning, adverbs check the meaning of the auxiliary in their scope, and this meaning consists both of a quantifier and a restrictor (an accessibility relation). Only if the two modal expressions are identical in these two respects, does a concord interpretation follow. Clearly, (C) certainly may $\rrbracket=\#$. And under the assumption that deontic may (henceforth may $_{\mathrm{d}}$ ) means $\lambda p \lambda w . \exists v\left[w R^{\prime} v \& v \in p\right]$, where $R^{\prime}$ denotes a deontic accessibility relation, the meaning of «(C) perhaps may $\rrbracket$ will also be undefined. Also note that since type-shifting is only optional, the theory has no problem predicting compositional readings, i.e. 【perhaps may $\mathrm{d}_{\mathrm{d}} \rrbracket$ is defined.

To sum up, when it comes to accounting for the semantic restrictions on modal concord, the type-shifting analysis does better than the syntactic

\footnotetext{
${ }^{15}$ Thanks to Kai von Fintel (p.c.) for pointing that out.
} 
agreement analysis. But it doesn't do better in all respects. While the agreement analysis reduces modal concord to a much more general phenomenon (i.e. syntactic agreement), which is obviously manifest in natural language, one is left wondering what motivates the type-shifting analysis. As it stands, the theory feels stipulative, a mere exercise in type writing. The problem is not that the theory cannot be extended to other phenomena (see Huitink (2008, 103-104) on the potential of analyzing negative concord in terms of (c), but rather that it isn't clear what the underlying intuition is. The theory seems more descriptive than explanatory. ${ }^{16}$ In the next section, I will present an alternative analysis, which combines ideas from the semantic type-shifting analysis with ideas from the syntactic agreement theory.

\subsection{Adverbs as domain restriction devices}

Above I have argued that given that modal verb-adverb combinations often allow both a concord and a compositional reading, it is not attractive to treat either modal verbs or modal adverbs as semantically empty. The alternative is postulating ambiguity, as in the type-shifting analysis. While I agree with that analysis that modal adverbs are ambiguous between a modal reading and a non-modal reading, I assume a different non-modal meaning for the relevant adverbs. That is, I propose to take the disambiguating function of modal concord as the point of departure, and treat modal adverbs as expressions that, on one of their meanings, merely serve to provide the restrictor for the modal they combine with.

Following Kratzer (1981, 1991), I assume that the meaning of modal expressions depends on two conversational backgrounds. The first is a factual background, which is called the modal base, and the second is a normative background, which is called the ordering source. The modal base supplies a set of propositions that jointly describe the set of accessible possible worlds. The ordering source ranks these worlds with respect to how well they conform to some given norm. Modal expressions like moeten 'must' quantify over those modal base-worlds that adhere to the norms in the ordering source as much as possible.

Formally, the modal base and ordering source are implemented as functions from worlds to sets of propositions, respectively $f$ and $g$. As said, the

\footnotetext{
${ }^{16}$ Bart Geurts (p.c.) suggests that the type-shifting analysis can be seen as a general approach to reinforcement by repetition, as in 'a long long time ago'. But I am not sure that there is much explanatory power in saying that the semantic function of the first occurrence of long is to 'test' whether the second occurrence of long has the right meaning. On the other hand, perhaps the point is that if modal concord is like reinforcement by repetition, one cannot reasonably demand a non-stipulative analysis.
} 
ordering source $g$, when applied to a world, gives the set of norms of that world, and this set determines a partial order $<_{g(w)}$ on set of possible worlds, as defined in (28a). Any given $g(w)$ determines a selection function $\max _{g(w)}$ which selects the $<_{g(w)}$-best worlds from a set of worlds $V$, according to the definition in $(28 \mathrm{~b}):^{17}$

$$
\begin{array}{ll}
\text { a. } & \text { For all worlds } u, v \in W: u<_{g(w)} v \text { iff } \\
& \{p: p \in g(w) \text { and } v \in p\} \subset\{p: p \in g(w) \text { and } u \in p\} . \\
\text { b. } & \text { For all } V \subseteq W: \\
& \max _{g(w)}(V)=\left\{w \in V: \text { there is no } v \in V: v<_{g(w)} w\right\} .
\end{array}
$$

Following recent implementations of Kratzer's semantics (von Stechow 2004), I assume that the modal base and the ordering source are the first and second argument of modals respectively. A corresponding entry for moeten 'must' is given in (29a). This is just the standard semantics for modal operators. The innovation I propose is that adverbs like verplicht 'obligatorily' may be used to fill the ordering source argument slot of moeten. That is, verplicht, on its non-quantificational interpretation, denotes a deontic ordering source, as in (29b):

$$
\begin{aligned}
& \text { a. } \quad \llbracket \text { moeten } \rrbracket=\lambda f \lambda g \lambda p \lambda w \cdot \max _{g(w)} \bigcap f(w) \subseteq \llbracket p \rrbracket \\
& \text { b. } \quad \text { verplicht } \rrbracket=\lambda w \lambda p \cdot p \text { is obliged in } w
\end{aligned}
$$

It is obvious that if verplicht has this meaning, moet verplicht will express a single modal quantifier (one that ranges over possible worlds that satisfy as much of the obligations in the world of evaluation as possible). Modal concord is thus accounted for.

But in how far are our three desiderata for an analysis of modal concord met? Clearly, the first, which is to account for the disambiguating effect of modal adverbs, is met. Second, the locality constraints are also met, given that it is usually assumed that the modal base and ordering source arguments of the modal are part of its projection. What about the semantic restrictions on modal concord? As the theory stands now, these are not explained. For example, (30) doesn't allow a concord reading:

Harry mag verplicht de afwas doen.

Harry may obligatorily the dishes do

'Harry is allowed to obligatorily do the dishes.'

Intuitively, a concord reading is not available for (30) because mag and ver-

\footnotetext{
${ }^{17}$ I thus presume that there always is a $<_{g(w)}$-best world, i.e. that the Limit Assumption (Lewis 1973) is justified.
} 
plicht are too far apart in the modal degree they express. But the analysis in (29), which says that on one of its readings, verplicht is just a domain restrictor, predicts the opposite.

The obvious way to repair the theory is to assume that verplicht, if read as a restrictor, comes with information about the quantification force of the modal it provides the restrictor for. Following Zeijlstra's agreement theory, I assume that verplicht comes with an uninterpretable feature $[\mathrm{u} \square]$. If verplicht combines with moeten, which carries [i $\square$ ], this feature is checked, but mogen, carrying $[\mathrm{i} \diamond]$ cannot check this feature. It follows that in combination with this verb, verplicht receives its familiar quantificational interpretation. ${ }^{18}$

Summing up, I propose that modal adverbs are devices for domain restriction that come with selectional restrictions concerning the modal force of the quantifier they are paired up with. Unlike the agreement theory and the type-shifting analysis, I am not assuming modal concord is the result of certain modals being semantically vacuous (as the agreement analysis claims that auxiliaries are, and as the type-shifting analysis claims that adverbs on their functional reading are). On this analysis, modal adverbs do have meaning, even in concord constructions.

\subsubsection{Comparison to the Lewis/Kratzer theory of if-clauses}

Under the present perspective, modal adverbs are similar to if-clauses. In Kratzer's $(1981,1991)$ doubly relative semantics, she argues that it is the pivotal role of if-clauses to restrict the domain of a higher operator: ${ }^{19}$

The history of the conditional is the story of a syntactic mistake. There is no two-place if . . then connective in the logical forms for natural languages. If-clauses are devices for restricting the domains of various operators. Whenever there is no explicit operator, we have to posit one. (Kratzer 1991, 656)

As pointed out by Geurts $(2005 \mathrm{a}, 392)$, there are two ways of reading this: either Kratzer proposes that a covert operator is posited only if an overt one is not present, or the two strategies for interpreting if-clauses are independent: it just needs to restrict some operator. This operator may be the overt quantifier in the scope of which the if-clause appears, or the if-clause may come with its own operator. Geurts argues that the second way of understanding Kratzer's theory is best. This implies that the combination of a

\footnotetext{
18 Alternatively, it could be that verplicht always denotes just an ordering source, and that a covert modal comes in to check its feature.

${ }^{19}$ Lewis (1975) already argued that some if-clauses function as mere domain restriction devices. Kratzer generalized the proposal to all if-clauses.
} 
quantifier and an if-clause always gives rise to ambiguity. Geurts (2005b) provides evidence that this is indeed the case. On the reading that Geurts favors, one could say that if-clauses are modal operators, which, in case they are combined with a modal verb, may turn into an expression that imposes further restrictions on the domain of the modal. The same seems true for adverbs like verplicht. If this adverb combines with an overt modal verb (of the right force), it may form one modal complex with this verb, imposing restrictions on its domain. Or it may introduce its own modal operator, resulting in a compositional reading.

There are also some differences between if-clauses and modal adverbs. First, Kratzer argues that if-clauses always restrict the modal base argument rather than the ordering source. Yet adverbs like verplicht seems to denote ordering sources. However, it has been argued that we also want some if-clauses to be able to provide restrictions on ordering sources (Sæbø 2001). Second, while it must be posited that verplicht only acts as a domain restrictor for a specific kind of modals (necessity) modals, this does not hold for if-clauses:

a. If you don't brush your teeth anymore, they might fall out.

b. If you have finished your homework, you may watch television.

In both of these sentences, the if-clause intuitively provides the set of worlds that the modal claim in the consequent is about. Yet in the absence of an overt quantifier, if-clauses are interpreted as restrictions on quantifiers with universal force:

a. If Harry is not in the library, he is in the common room. $\approx$ If Harry is not in the library, he must be in the common room.

b. If it rains, it pours. $\approx$ Always if it rains, it pours.

It could be that there is a general trend for modal operators to become used as restriction devices for higher modal operators. It is to be expected that this particularly happens to those expressions that are rich in semantic content (i.e. for which the modal flavor is clear), as for these expressions, it is easy to detect the restrictor that is contributed.

\subsubsection{Comparison to Shields' account of 'modal repair'}

My proposal seems to be exactly the opposite of Shields' (to appear) account of 'modal repair'. Modal repair is the phenomenon that the insertion of a modal auxiliary may rescue sentences in which a modal adverb occurs that 
would otherwise be degraded. For instance, it is well-known that epistemic adverbs are bad in questions, e.g. Bellert (1977), McDowell (1987). But as Shields points out, grammaticality can be repaired by including an auxiliary. The following examples illustrate this:
a. *Is she possibly the best in the competition?
b. Could she possibly be the best in the competition?
c. *Did John probably check this before we sent it out?
d. Should John probably check this before we sent it out?

Shields convincingly argues that existing accounts of why (33a) and (33c) are bad, do not explain why (33b) and (33d) are good. As an alternative she proposes that (i) modal auxiliaries are ambiguous between a modal reading and a non-modal reading under which they only specify a restriction, while (ii) modal adverbs only denote a modal force. As all natural language quantifiers require a restriction, adverbs need to be paired up with either a modal auxiliary (on its non-modal reading), or with a covert epistemic background EPIS. Shields assumes that EPIS is projected in C and that EPIS cannot be present in $\mathrm{C}$ together with a question-operator. This explains why (33c) is ungrammatical (the adverb has no restrictor), and why (33d) is fine (could has no problems co-occuring with a question-operator in $\mathrm{C}$ ).

$$
\begin{aligned}
& \text { a. } \left.\left.\left.*\left[{ }_{\mathrm{CP}}[\mathrm{C} \text { Question OP-did [John t [probably [check this }]\right]\right]\right]\right] ? \\
& \text { b. *[C }[\mathrm{C} \text { Question OP-EPIS [John t [probably [check this]]]]]? } \\
& \text { c. }{ }_{\mathrm{CP}}[\mathrm{C} \text { Question OP-should [John t [probably [check this]]]]]? }
\end{aligned}
$$

Interestingly, Shields points out that not any modal can repair: the adverb and auxiliary need to be similar in quantificational force. For instance, while could can repair sentences with possibly, it cannot do so for sentences with probably. To deal with his, Shields assumes that modals like could come with a feature which indicates the type of quantificational force the restriction they express needs to be paired up with.

Thus, Shields' treatment of auxiliaries and adverbs is opposite to mine. She assumes that the modal flavor of auxiliaries is lexically given, whereas I follow the Kratzerian canon and assume that it is not specified in the lexicon, but needs to be filled in by the context of utterance (whereas adverbs are semantically richer; i.e. their flavor usually is specified). Yet Shields' theory and mind need not be incompatible. That is, the essence of her proposal is that adverbs need to form a quantifier-restriction relationship, and that they need an overt modal to achieve this in questions. She assumes that modal adverbs just denote a modal force, but as far as I can tell, one could just as well say that such adverbs just just denoting restrictions. They would then 
need to be paired with either an overt quantifier, or a covert one, and if we assume that a covert quantifier may not co-occur with the question-operator in $\mathrm{C}$, the facts follow. However, it remains to be seen if such an analysis is feasible.

\section{Conclusions and future research}

In this paper we have seen that modal concord is a natural and pervasive phenomenon, at least in Dutch. I have argued that modal concord poses a challenge to compositional semantics, and is therefore in need of an explanation. Two analyses are already on the market. There is the syntactic agreement theory, which I have argued to be too rigorous to deal with modal concord, and there is the semantic type-shifting analysis, which I have argued to be too ad hoc. As an alternative, I have proposed to analyze modal adverbs as domain restriction devices, parallel to if-clauses. Yet unlike ifclauses, I have proposed that adverbs come with information of the modal force of the operator for which they provide the restriction.

There are many issues I have to leave for future research. First, we would like to know more about the cross-linguistic manifestation of modal concord. My analysis predicts that concord readings do not occur with modal verbs that have a rich semantics (i.e. that are specified for modal flavor). More research is needed to see if this is really borne out. Second, my analysis has nothing to say about negative concord. It remains to be seen whether it is justified to tease these two concord phenomena apart. At this point, I can only say that there doesn't seem to be a single theory around yet, that can cope with both. In this paper I have argued against the syntactic agreement theory. Yet its main contender, that analyzes negative concord in terms of polyadic quantification, doesn't seem to fare better. De Swart \& Sag (2002) define a mechanism of quantifier resumption: if two 'similar' quantifiers both bind variables of a subset of a domain of discourse E, the resumptive quantifier binds pair variables that are members of a subset of $\mathrm{E}^{2}$. Thus, the logical form for 'No one loves no one' contains one quantifier which ranges over pairs of human beings. But for modal concord, this analysis doesn't seem to work. For example, the resumption of may and perhaps to one quantifier ranging over pairs of worlds $w, v$ such that $w R v$ and $v R u$, will still involve a double layer of modality. Finally, we saw that my analysis is not compatible with Shields' account for modal repair. I have suggested a way to repair this (essentially by changing Shields' theory). Future research is needed to determine whether this is correct. 


\section{Author's address}

Janneke Huitink

's Gravensandestraat 12

6533 NT Nijmegen

the Netherlands

\section{Acknowledgments}

I would like to thank Bart Geurts, Hedde Zeijlstra, Paul Dekker and Kai von Fintel for comments on earlier versions of this paper. I am also grateful to the audiences of the Nijmegen Semantics Colloquium and of Sinn und Bedeutung 11 for helpful remarks.

\section{References}

Bellert, Irena. 1977. On semantic and distributional properties of sentential adverbs. Linguistic Inquiry 8: 337-417.

Chellas, Brian F. 1980. Modal logic: an introduction. Cambridge: Cambridge University Press.

Chomsky, Noam. 1995. The minimalist program. Cambridge, MA: MIT Press.

Cinque, Guglielmo. 1999. Adverbs and functional heads: a crosslinguistic perspective. Oxford: Oxford University Press.

Drubig, Hans Bernhard. 2001. On the syntactic form of epistemic modality. Manuscript. Universität Tübingen.

www.sfb441.uni-tuebingen.de/b2/papers/DrubigModality.pdf .

Geurts, Bart. 2005a. Entertaining alternatives: disjunctions as modals. Natural Language Semantics 13: 383-410.

Geurts, Bart. 2005b. On an ambiguity in quantified conditionals. Manuscript, University of Nijmegen. http://www.ru.nl/ncs/bart/papers/conditionals.pdf.

Geurts, Bart \& Janneke Huitink. 2006. Modal concord. In Paul Dekker \& Hedde Zeijlstra (eds.) Proceedings of the ESSLLI 2006 workshop 'concord phenomena at the syntaxsemantics interface', 15-20. University of Málaga.

Greenbaum, Sidney. 1970. Verb-intensifier collocations in English. The Hague: Mouton de Gruyter.

Grosz, Patrick. 2008. Particle-izing imperatives. Manuscript, Massachusetts Institute of Technology.

http://web.mit.edu/grosz/www/grosz_imperatives_v1.pdf. 
Halliday, Michael Alexander Kirkwood. 1970. Functional diversity in language as seen from a consideration of modality and mood in English. Foundations of Language 6: $322-361$.

Horn, Laurence R. 1984. Toward a new taxonomy for pragmatic inference: Q-based and R-based implicatures. In Deborah Schiffrin (ed.) Meaning, form and use in context, 11-42. Washington, D.C.: Georgetown University Press.

Hoye, Leo. 1997. Adverbs and modality in English. London and New York: Longman.

Huitink, Janneke. 2008. Modals, conditionals and compositionality. Ph.D. thesis, Radboud University Nijmegen.

Kratzer, Angelika. 1981. The notional category of modality. In Hans-Jürgen Eickmeyer \& Hannes Rieser (eds.) Words, worlds and contexts: New approaches in word semantics, 38-74. Berlin: Walter de Gruyter.

Kratzer, Angelika. 1991. Modality/Conditionals. In Arnim von Stechow \& Dieter Wunderlich (eds.) Semantik: ein internationales Handbuch der zeitgenössischen Forschung/Semantics: An international handbook of contemporary research, 639-656. Berlin: De Gruyter.

Lewis, David K. 1973. Counterfactuals. Cambridge, MA: Harvard University Press.

Lewis, David K. 1975. Adverbs of quantification. In Edward L. Keenan (ed.) Formal semantics of natural language: papers from a colloquium sponsored by the King's College Research Centre, 3-15. Cambridge: Cambridge University Press.

Lyons, John. 1977. Semantics. Cambridge: Cambridge University Press.

McDowell, Joyce. 1987. Assertion and modality. Ph.D. thesis, University of Southern California.

McNamara, Paul. 2008. Deontic logic. In Edward N. Zalta (ed.) The Stanford Encyclopedia of Philosophy (Fall 2008 edition). Forthcoming at http://plato.stanford.edu/archives/fall2008/entries/logic-deontic/.

Nauze, Fabrice. 2008. Modality in typological perspective. Ph.D. thesis, University of Amsterdam.

Nordlinger, Rachel \& Elizabeth Closs Traugott. 1997. Scope and development of epistemic modality: Evidence from ought to. English Language and Linguistics 1(2): 295-317.

Nuyts, Jan. 2001. Epistemic modality, language, and conceptualization: a cognitivepragmatic perspective. Amsterdam: John Benjamins.

Nuyts, Jan. 2004. Over de beperkte combineerbaarheid van deontische, epistemische en evidentiële uitdrukkingen in het Nederlands. Antwerp Papers in Linguistics 108.

Papafragou, Anna. 2000. Modality: Issues in the semantics-pragmatics interface. Amsterdam/New York: Elsevier Science. 
Portner, Paul. 1997. The semantics of mood, complementation, and conversational force. Natural Language Semantics 5(2): 167-212.

Prior, Arthur N. 1955. Formal logic. Oxford: Clarendon Press.

Sæbø, Kjell Johan. 2001. Necessary conditions in a natural language. In Caroline Féry \& Wolfgang Sternefeld (eds.) Audiatur vox sapientiae: a festschrift for Arnim von Stechow, 427-449. Berlin: Akademie Verlag.

Shields, Rebecca. to appear. Modal repair and quantifier restriction: epistemic adverbs in c operator clauses. Ms. University of Wisconsin-Madison. To appear in Natural Language and Linguistic Theory.

von Stechow, Arnim. 2004. Modale und Konditionale. Handout of a course taught at the University of Vienna.

http://www2.sfs.uni-tuebingen.de/ arnim10/Handouts/Modalitaet.pdf.

de Swart, Henriëtte \& Ivan Sag. 2002. Negation and negative concord in Romance. Linguistics and Philosophy 25(4): 373-417.

Sweetser, Eve. 1990. From etymology to pragmatics: metaphorical and cultural aspects of semantic structure. Cambridge: Cambridge University Press.

von Wright, Georg Henrik. 1951. Deontic logic. Mind 60(237): 1-16.

Zeijlstra, Hedde. 2004. Sentential negation and negative concord. Ph.D. thesis, University of Amsterdam.

Zeijlstra, Hedde. 2007. Modal concord is syntactic agreement. Forthcoming in the Proceedings of SALT 17, CLC Publications, Ithaca, NY.

http://ling.auf.net/lingBuzz/000494. 